\title{
Article \\ Controlled Over-Expression of AtDREB1A Enhances Tolerance against Drought and Salinity in Rice
}

\author{
Raveendran Muthurajan ${ }^{1, *,+}$, Valarmathi Ramanathan ${ }^{1,+}$, Abhijeet Bansilal Shillak ${ }^{1}$, \\ Suryawanshi Madhuri Pralhad ${ }^{1}$, Chavan Neha Shankarrao ${ }^{1}$, Hifzur Rahman ${ }^{1,2} \mathbb{D}$, Rohit Kambale ${ }^{1}$, \\ Jagadeeshselvam Nallathambi ${ }^{1}$, Sudha Tamilselvan ${ }^{1}$ and Parani Madasamy ${ }^{3}$ \\ 1 Centre for Plant Molecular Biology and Biotechnology, Department of Plant Biotechnology, \\ Tamil Nadu Agricultural University, Coimbatore, Tamil Nadu 641003, India; \\ valarmathimssrf@gmail.com (V.R.); abhijeetshillak@gmail.com (A.B.S.); madhurithebest@gmail.com (S.M.P.); \\ chavanneha2513@gmail.com (C.N.S.); rahman.biotech@gmail.com (H.R.); rohitkamble568@gmail.com (R.K.); \\ njsphd@gmail.com (J.N.); sudhatamil@gmail.com (S.T.) \\ 2 International Center for Biosaline Agriculture, Dubai 4375, UAE \\ 3 Department of Genetic Engineering, SRMIST, Chennai, Tamil Nadu 603203, India; mparani@gmail.com \\ * Correspondence: raveendrantnau@gmail.com; Tel.: +91-422-6611353; Fax: +92-422-6611462 \\ + Both authors contributed equally to this work.
}

check for

updates

Citation: Muthurajan, R.;

Ramanathan, V.; Bansilal Shillak, A.; Madhuri Pralhad, S.; Shankarrao,

C.N.; Rahman, H.; Kambale, R.;

Nallathambi, J.; Tamilselvan, S.;

Madasamy, P. Controlled

Over-Expression of AtDREB1A

Enhances Tolerance against Drought and Salinity in Rice. Agronomy 2021

11, 159. https://doi.org/10.3390/

agronomy11010159

Received: 4 December 2020

Accepted: 5 January 2021

Published: 16 January 2021

Publisher's Note: MDPI stays neutral with regard to jurisdictional clai$\mathrm{ms}$ in published maps and institutional affiliations.

Copyright: $(\odot 2021$ by the authors. Licensee MDPI, Basel, Switzerland. This article is an open access article distributed under the terms and conditions of the Creative Commons Attribution (CC BY) license (https:// creativecommons.org/licenses/by/ $4.0 /)$.
Abstract: Engineering transcription factors (TF) hold promise in enhancing abiotic stress tolerance in plants. In this study, one of the popular rice varieties of South India, namely ADT 43, was engineered with a TF AtDREB1A driven by a stress-inducible $r d 29 A$ promoter. PCR and Southern hybridization were employed to confirm the integration and copy number of the transgene. Transgenic lines $\left(\mathrm{T}_{1}\right)$ of ADT 43 showed enhanced tolerance to drought and salinity compared to the non-transgenic ADT 43. Transgenic lines were found to maintain higher RWC \%, lower leaf temperature, and partially closed stomata, enabling better survival under stress conditions. qRT-PCR analysis revealed the strong induction of AtDREB1A transcripts during drought. Transgenic lines of ADT 43 exhibited increased germination and retention of chlorophyll in their leaves under salinity. Evaluation of transgenic lines under transgenic screen house conditions revealed that line \# A16 exhibited on par agronomic performance against its non-transgenic counterpart under normal conditions. Under drought, non-transgenic ADT 43 showed $>20 \%$ reduction in the total number of spikelets per panicle, whereas transgenic line \# A16 registered only a 2\% reduction. Non-transgenic ADT 43 recorded $80 \%$ yield reduction under drought, whereas line \# A16 recorded only 54\% yield loss. The above results demonstrated the effectiveness of controlled expression of DREB1A in regulating dehydration responses in rice.

Keywords: DREB1A; drought; salinity tolerance

\section{Introduction}

Drought, salinity, and temperature extremes are the most common environmental factors limiting crop productivity. Sustained increase in food grain production depends mainly on developing climate-resilient crop varieties [1]. Accelerated genetic improvement of complex traits like drought/salinity tolerance has been achieved through marker-assisted selection and genetic engineering. A thorough understanding of molecular responses is a prerequisite for discovering candidate genes underlying stress tolerance. Plants respond to abiotic stresses through a complex network of physiological, biochemical, and molecular mechanisms. Among the various molecular processes, the mechanism of stress perception and cell signaling plays an essential role in altering the plant's ability to survive under abiotic stress conditions [2-7]. In the tolerant genotypes, perception of stress signals initiated early during the onset of stress reprograms the activation of a large set of stress-responsive genes through different transcription factors (TFs) [8,9]. Recently, numerous studies have 
shown that Transcription Factors (TFs) play an important role in regulating the responses against various stresses in plants [10]. A large number of TF families' viz., AP2/ERF, NAC, bZIP, ABRF, MYB, WRKY, homeodomain, and bHLH have been reported to play crucial roles in abiotic stress tolerance in plants [11-13].

Among various stress-responsive TFs, the APETALA2/ETHYLENE RESPONSIVE FACTOR (AP2/ERF) family has drawn the attention of several researchers due to its key role in modulating gene expression in response to multiple stresses and hormones [14-16]. Dehydration Responsive Element Binding (DREB) TFs are one of the key members of ERF family of transcription factors involved in the ABA-independent signal transduction pathway and are responsible for controlling osmoprotection and metabolism [17] and modulating gene expression against cold, drought, salinity, etc. [18]. The dehydration responsive element (DRE) with a 9 bp conserved core sequence $\left(5^{\prime}\right.$-TACCGACAT- $\left.3^{\prime}\right)$ was first identified in the promoter of the drought-responsive gene $r d 29 A$ [19] to which $D R E B$ transcription factor binds and regulates the expression of many stress-responsive genes. DREB1 /CBFs were reported to be induced by cold stress, and ectopic expression of CBF1, $\mathrm{CBF} 3$, and $\mathrm{CBF} 4$ significantly improved plant's tolerance to low-temperature and activates the expression of COR genes [20]. DREB2A and DREB2B are induced by drought and salinity but not by cold [21-23]. Over-expression of DREB1A conferred increased tolerance against drought, salinity, and cold stresses in Arabidopsis [21,24]. DREB1A was reported to activate several stress tolerant genes viz., rd29A, kin1, Cor 6.6, Cor 15a, rd17, erd10, erd1, and P5CS, as well as the expression of their direct downstream genes with DRE-cis element, such as RD29A, COR15A, ERD10, COR47 and GoLS2 [25,26].

Over-expression of DREB1A driven by a constitutive CaMV35S promoter resulted in growth abnormalities [27]. Such adverse effects were mitigated through the engineered expression of DREB1A driven by a stress-inducible promoter $r d 29 A$ [28-30]. In this study, $A t D R E B 1 A$ cloned under the control of stress-inducible promoter $r d 29 A$ was used for engineering drought tolerance in a popular rice variety ADT43. Transgenic rice lines $\left(\mathrm{T}_{1}\right)$ were subjected to thorough molecular characterization and superior lines were evaluated for measuring their responses against drought and salinity.

\section{Results}

\subsection{Development of Transgenic ADT 43 Lines and Molecular Analysis}

Embryogenic calli from immature embryos of ADT 43 were co-cultivated with $A$. tumefacians-harboring pCAMBIA 1300 engineered with AtDREB1A (Figure 1a,b). A total of 47 putative transgenic plants were regenerated and used for further characterization. $\mathrm{Pu}-$ tative transgenic plants ( $\mathrm{T}_{0}$ generation) were confirmed by PCR analysis using primers specific to hygromycin (hpt) and the transgene AtDREB1A. Out of 47 progenies, 45 showed the presence of expected amplicon of $548 \mathrm{bp}($ AtDREB1A) and $630 \mathrm{bp}$ (hpt gene) (Figure 1c). Southern hybridization analysis using radio-labeled $\left(\mathrm{P}^{32}\right)$ hpt gene (selectable marker) identified both single copy and multiple copy insertions (Figure 1d). Transgenic lines $\left(\mathrm{T}_{0}\right)$ viz., A16, A17, A19, B5, B9, and B16 and were found to have single-copy integration of the transgene construct while few other lines viz., C3 and B13 were found to have multiple copy insertions.

\subsection{Evaluation of Transgenic ADT 43 ( $T_{1}$ Generation) against Drought and Salinity \\ 2.2.1. Drought Responses \\ Transgenic ADT 43 Lines Exhibited Enhanced Tolerance against Drought}

Non-transgenic ADT43 plants showed leaf rolling and wilting symptoms on 18 DAIS (days after imposing stress) at which the transgenic lines (B9, A16, and C3) did not show any rolling or wilting symptoms. Leaves of transgenic lines were found to be turgid and green even on 18 DAIS at which non-transgenic plants developed severe leaf drying symptoms (Figure 2). Transgenic lines \# B9 and \# C3 did not show any delay in their flowering behavior (Figure 2). Upon re-watering, all the transgenic plants exhibited better recovery, whereas the non-transgenic plants of ADT 43 failed to recover (Figure 2). 
a.

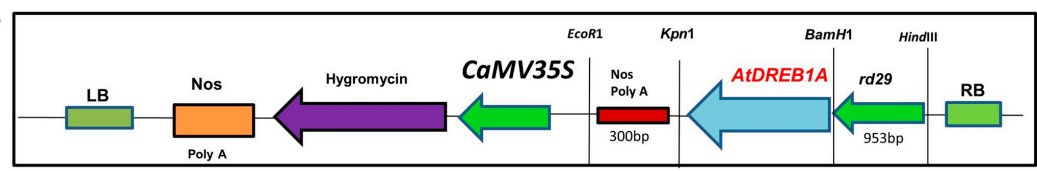

b.

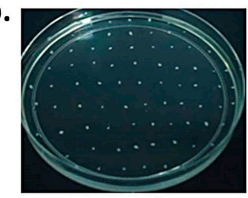

a. ADT 43 immature As medium before infection agrobacterium infection

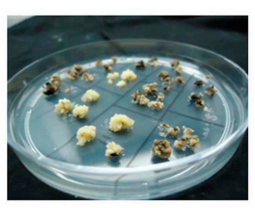

e. Proliferated calli on

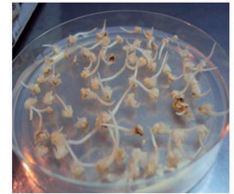

c. Immature Embryos after cocultivation on NB-As Media
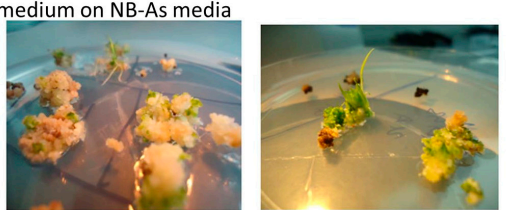

g. Shoot development on regeneration (RNMH75) medium

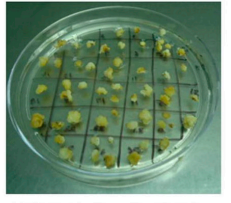

d. Sub-cultured calli on resting (CCMC) medium

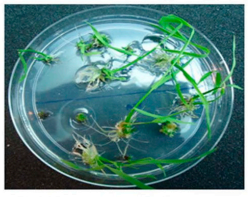

h. Putative transgenic plantlets on half MS medium under rooting
C.
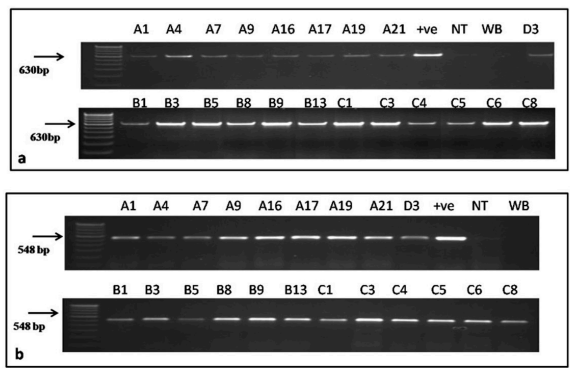

d.

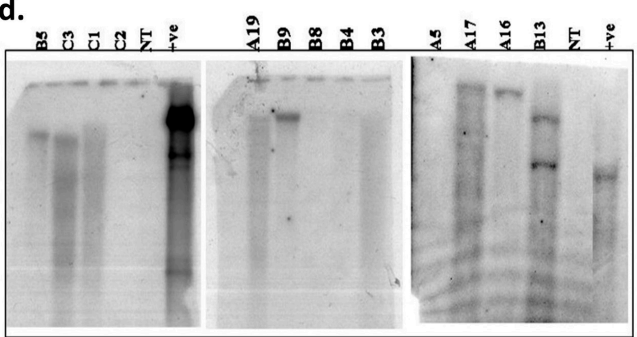

Figure 1. Development of transgenic rice (ADT 43) lines and molecular analysis (a) map of pCAMBIA 1300 harboring AtDREB1A under the control of stress-inducible promoter $r d 29 A$ (b) Agrobacterium-mediated transformation of rice (ADT 43) (c) PCR analysis of transgenic and non-transgenic (NT) ADT 43 lines showing the amplification of hygromycin (hpt) gene (630 bp) and AtDREB1A gene (548 bp), WB-Water Blank (d) Southern hybridization analysis of transgenic and non-transgenic ADT 43 lines; $25 \mu \mathrm{g}$ genomic DNA digested with BamHI and transferred to nylon membrane and hybridized with radiolabeled hygromycin probe. Blots show different transgenic, non-transgenic (NT), and positive plasmid-harboring AtDREB1A (+ve).

18 DAIS
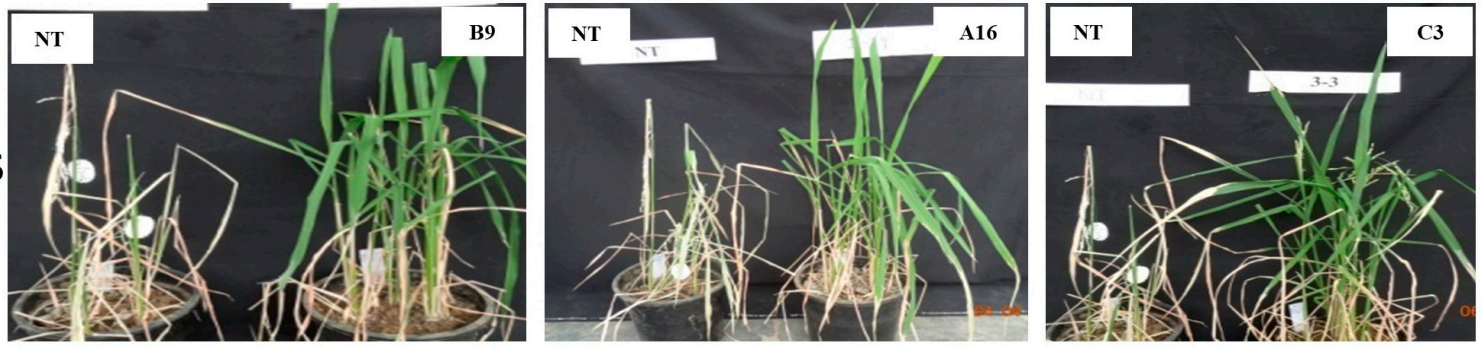

14 DAR
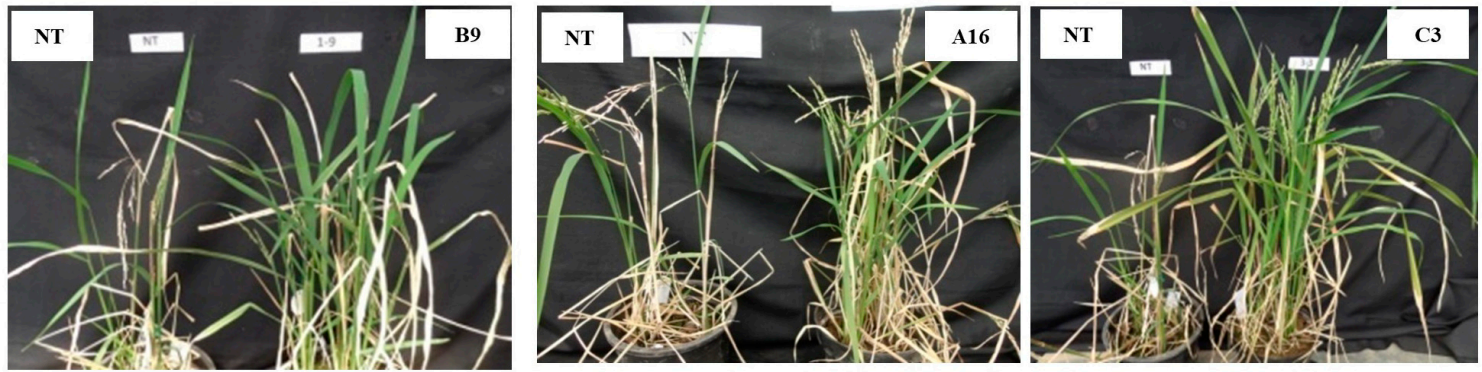

Figure 2. Responses of transgenic and non-transgenic ADT43 $\left(\mathrm{T}_{1}\right)$ lines to drought (18 DAIS) and re-watering (14 days after re-watering).

Transgenic Lines Maintained Higher RWC and Lower Leaf Temperature

Relative water content in the leaves of both transgenic and non-transgenic ADT43 was found to decrease during the progression of drought. On 13 DAIS, leaves of non-transgenic ADT 43 were found to retain $77.7 \%$ of RWC, whereas it ranged between $79.6-90 \%$ among the transgenic lines (Figure 3a). On 18 DAIS, RWC in the leaves of non-transgenic ADT 
43 reached $65.29 \%$, whereas it ranged between $75-84 \%$ among the transgenic lines. The transgenic lines viz., B9 and A16 were found to contain $>80 \%$ RWC (Figure 3a).
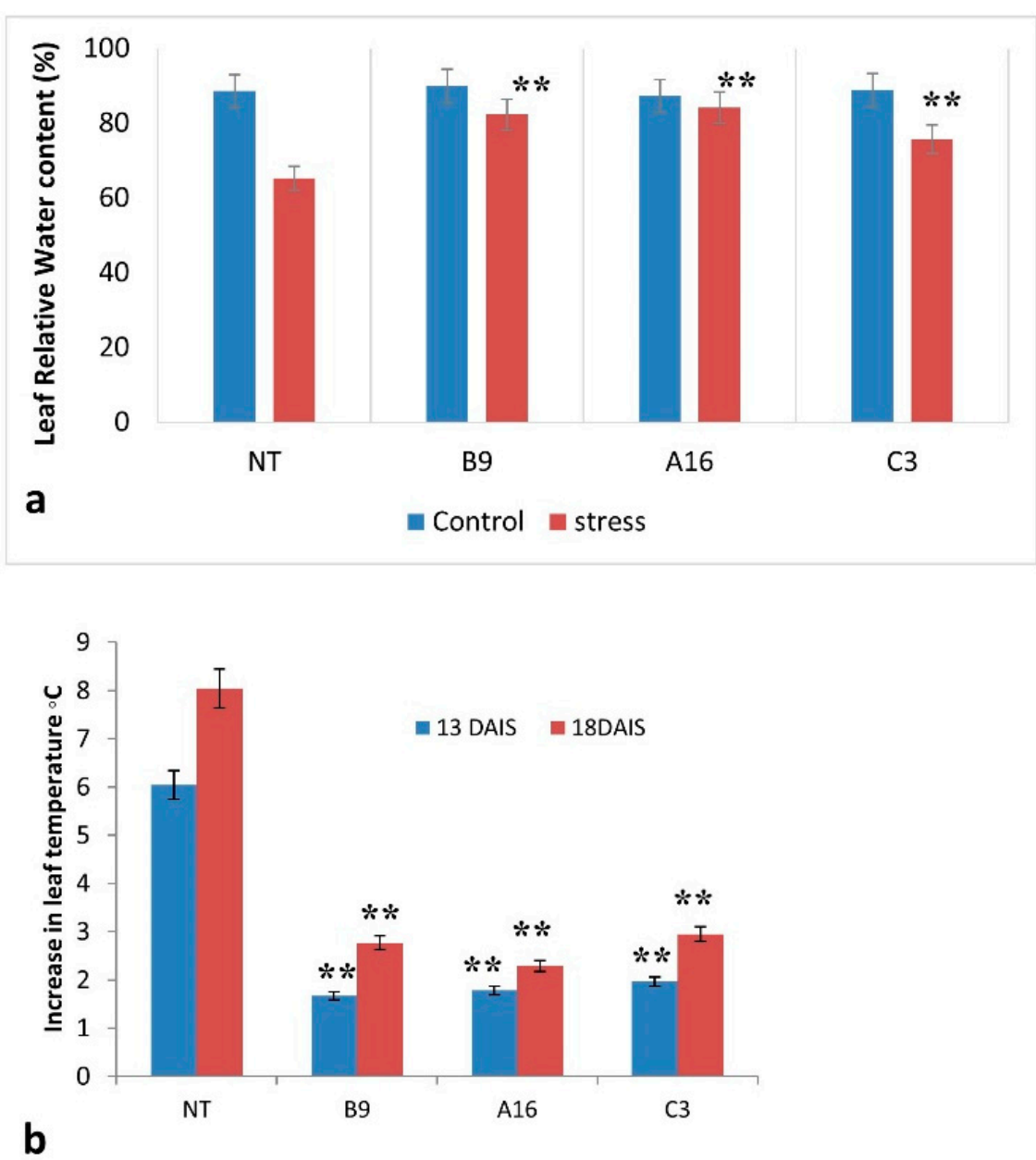

Figure 3. Relative water content (RWC) and temperature (increase over control) in the leaves of transgenic and non- transgenic ADT 43; (a) Relative water content measured on 18 DAIS; (b) increase in the leaf temperature of stressed plants over controls on 13 DAIS and 18 DAIS; NT, Non-transgenic ADT 43. Values are mean of three replications and ${ }^{* *}$ indicates statistical significance at $p<0.01$ (ANOVA compared to non-transgenic data).

Internal tissue temperature of the leaves was measured in the control and drought subjected plants of both transgenic and non-transgenic ADT 43 (once on 13 DAIS and secondly on 18 DAIS). Leaf temperature was found to increase during the progression of drought, and the increase was more in the non-transgenic plants (Figure 3b). Droughtstressed (13 DAIS) plants of non-transgenic ADT 43 recorded an increase of $6{ }^{\circ} \mathrm{C}$ when compared to its well-watered control, whereas the transgenic plants recorded an increase of up to $2{ }^{\circ} \mathrm{C}$ (Figure $3 \mathrm{~b}$ ). On 18 DAIS, the NT plants with clear leaf drying symptoms showed an increased leaf temperature of $8{ }^{\circ} \mathrm{C}$ than their control plants. The transgenic lines (B9, A16 and C3) showed only $2-4{ }^{\circ} \mathrm{C}$ increase in their leaf temperature against their respective controls (Figure $3 b$ ).

Transgenic Plants Exhibited Better Stomatal Control to Maintain Cellular Activities

Regulation of stomatal opening/closure is one of the vital mechanism(s) in maintaining $\mathrm{CO}_{2}$ assimilation and canopy cooling. Intermittent drought stress caused the complete closure of stomata in the leaves of non-transgenic ADT 43, whereas stomata remained partially opened in the leaves of transgenic ADT 43 lines. Scanning Electron Microscopic 
analysis revealed that transgenic plants were found to contain intact papillae and leaf hairs during drought, whereas they were found to be deformed during the drought in the non-transgenic ADT 43 (Figure 4a,b).
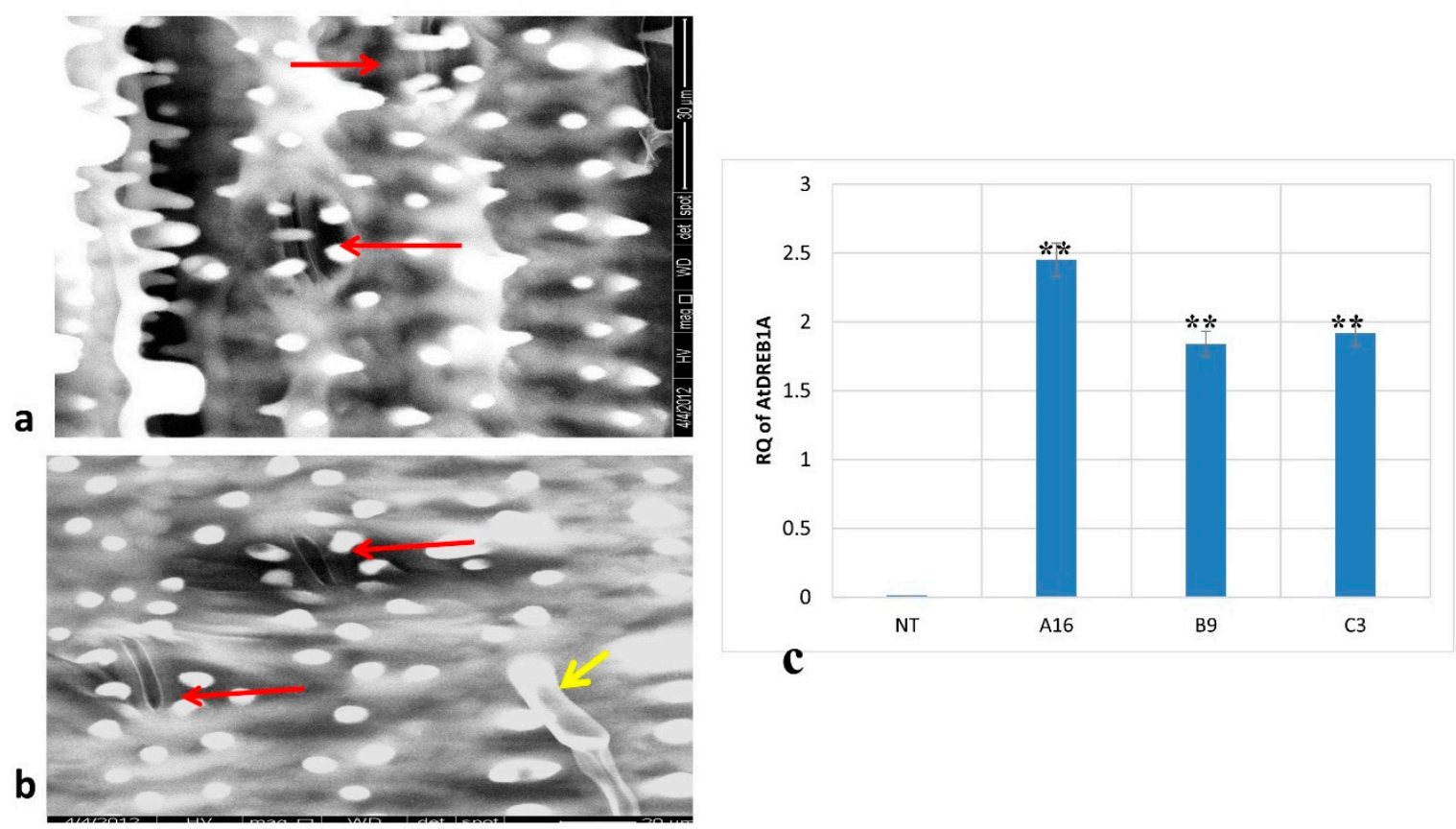

Figure 4. Scanning electron microscopic view of leaves from non- transgenic and transgenic ADT 43 (Event \# A16) at 18 DAIS; (a) Non-transgenic leaf showing fully closed stomata on 18 DAIS (30 $\mu \mathrm{m})$; (b) Transgenic (\# A16) leaf showing partially opened stomata at the same time. Red arrow indicates the stomata, and yellow arrow indicates the leaf hairs; (c) qRT-PCR analysis of AtDREB1A transcripts in non-transgenic (NT) and transgenic ADT43 lines. Values are mean of three replications, and ${ }^{* *}$ indicates statistical significance at $p<0.01$ (ANOVA compared to non-transgenic).

Transgenic Plants Exhibited a Strong Induction of AtDREB1A during Drought Stress

Total RNA isolated from control and drought-stressed (18 DAIS) leaf samples of transgenic lines A16, B9 and C3 were subjected to qRT-PCR analysis of the transgene AtDREB1A along with non-transgenic ADT 43. The qRT-PCR analysis revealed the strong induction of AtDREB1A transcripts only in the transgenic lines, whereas there was no expression in non-transgenic ADT 43 and control plants (Figure 4c).

\subsubsection{Salinity Responses}

Transgenic Plants Exhibited Higher Germination Percentage under Salinity Stress

Transgenic lines were evaluated for their ability to germinate under salinity by germinating them under different concentrations of $\mathrm{NaCl}$ along with their non-transgenic counterpart. The germination percentage was calculated based on the number of seeds germinated on 8 DAS (days after sowing), which reduced with increasing $\mathrm{NaCl}$ stress in both non-transgenic and transgenic ADT 43 (Figure 5a). At $50 \mathrm{mM}$ and $100 \mathrm{mM} \mathrm{NaCl}$ stress, the transgenic lines were found to exhibit significantly greater percentage of germination than the non-transgenic ADT 43 (Figure 5b). Transgenic lines showed 70-80\% germination at $50 \mathrm{mM}$ and $60-70 \%$ germination in $100 \mathrm{mM} \mathrm{NaCl}$ (Figure 5b). At $200 \mathrm{mM} \mathrm{NaCl}$ stress, only the two transgenic lines B9 and A16 showed 10\% germination. Shoot length and root length were recorded on 8 DAS. All the lines exhibited significant growth retardation under $\mathrm{NaCl}$ stress, but the effect was more pronounced in the non-transgenic ADT 43. At $50 \mathrm{mM} \mathrm{NaCl}$ stress, the mean shoot length of non-transgenic ADT 43 was $2.45 \mathrm{~cm}$, whereas the transgenic lines recorded 2.87-4.2 cm (Figure 6a). Non-transgenic ADT 43 plants did not develop any roots under salinity (50 mM and $100 \mathrm{mM})$, whereas the transgenic lines 
recorded $0.23-1.36 \mathrm{~cm}$ of root length at $50 \mathrm{mM}$ and $0.17-0.4 \mathrm{~cm}$ at $100 \mathrm{mM} \mathrm{NaCl}$ (Figure $6 \mathrm{~b}$ ). At $50 \mathrm{mM}$ and $100 \mathrm{mM} \mathrm{NaCl}$ stress, all the transgenic lines were found to have a greater vigor index than the non-transgenic ADT 43 (Figure 6c).
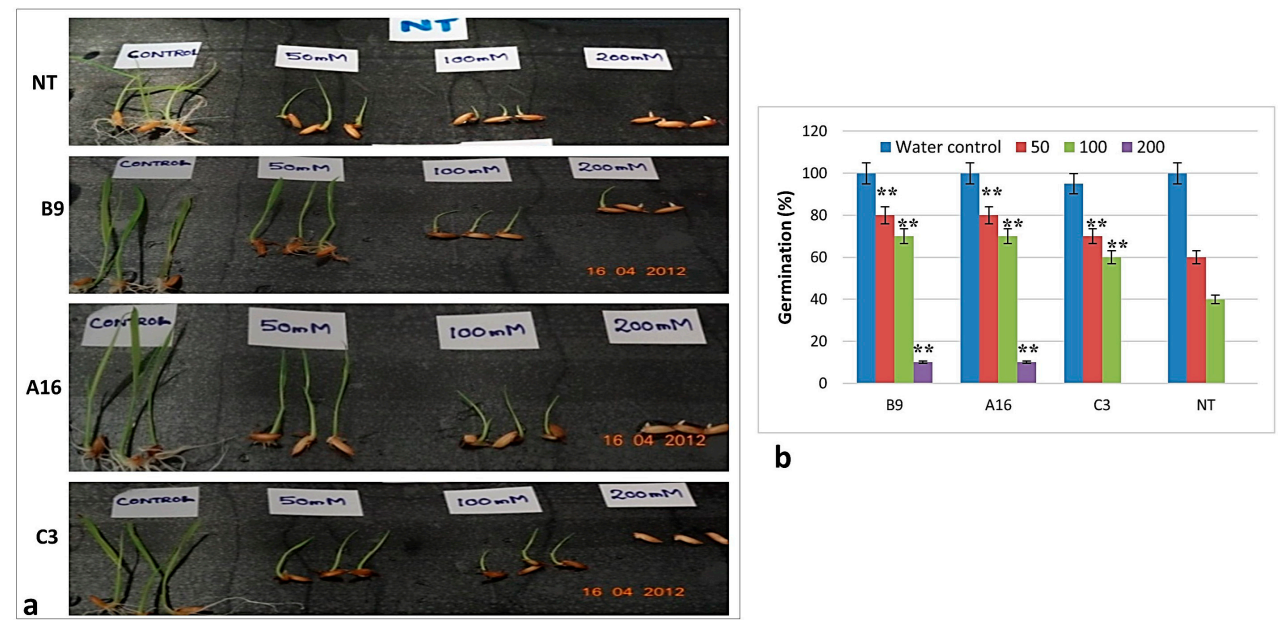

b

Figure 5. Evaluation of transgenic and non-transgenic ADT 43 lines ( $\left.T_{1}\right)$ for their ability to germinate under 50, 100, and 200 $\mathrm{mM} \mathrm{NaCl}$ stress; (a) Phenotype of transgenic and non-transgenic ADT 43 seedlings germinated at different concentration of $\mathrm{NaCl} ;(\mathbf{b})$ Germination percentage of transgenic and non-transgenic ADT 43 (NT). Values are mean of fifteen replications and ${ }^{* *}$ indicates statistical significance at $p<0.01$ (ANOVA compared to non-transgenic ADT 43).
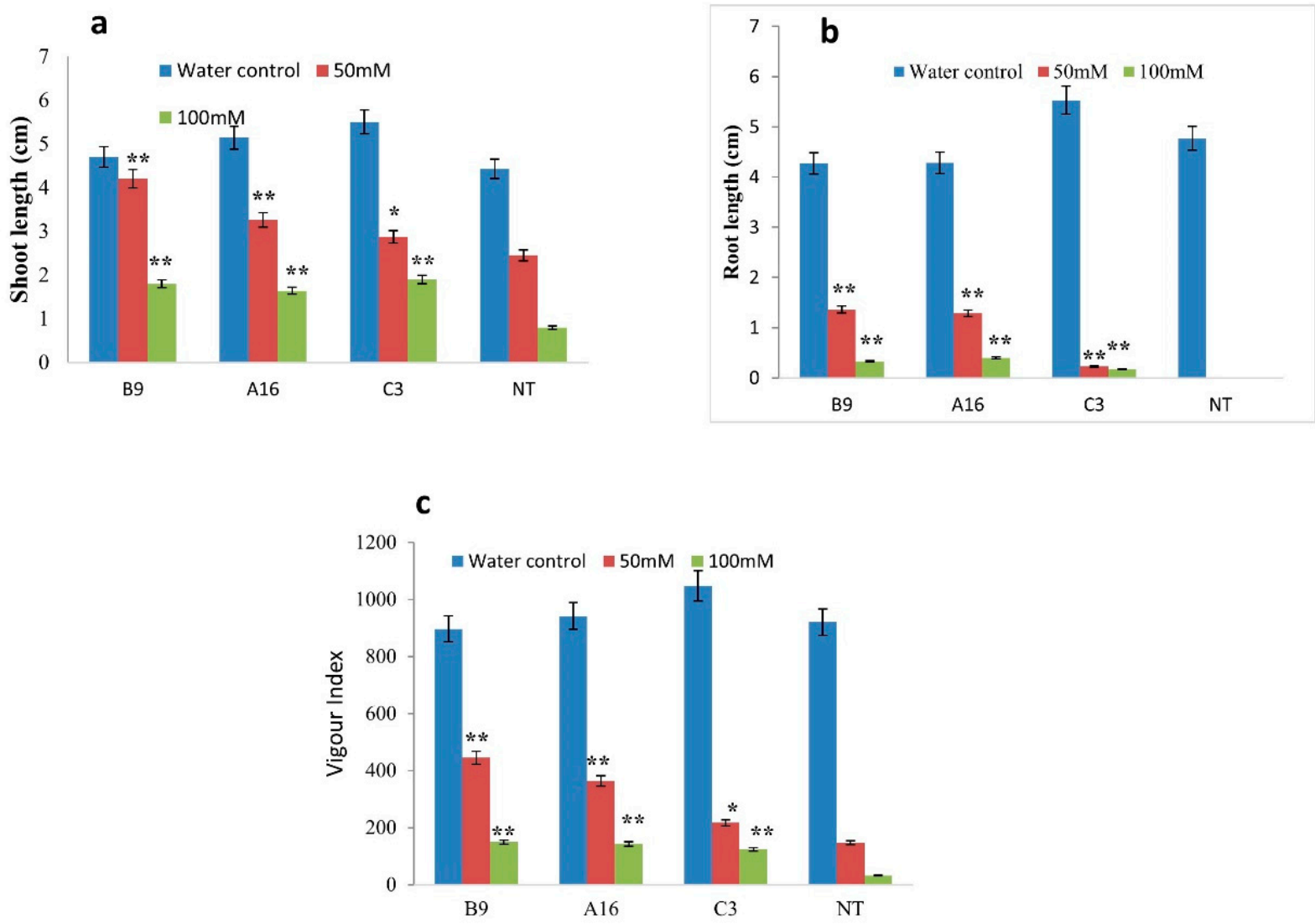

Figure 6. Shoot length; (a) root length; (b) and Vigor Index; (c) measured in non-transgenic (NT) and transgenic ADT $43\left(\mathrm{~T}_{1}\right)$ seedlings germinated at different levels of $\mathrm{NaCl}$ concentration. Each value is a mean of fifteen replications. ** indicates statistical significance at $p<0.01$ and * indicates significance at $p<0.05$ (ANOVA compared to non-transgenic salinity stressed). 
Leaf Discs of Transgenic Plants Exhibited Slower Degradation of Chlorophyll

Leaf discs collected from the non-transgenic and transgenic plants were floated on $50 \mathrm{mM}, 100 \mathrm{mM}$, and $200 \mathrm{mM} \mathrm{NaCl}$ solution. Water was used as a control. Periodical observations were made to measure the development of yellowing symptoms on the discs. Leaf discs of non-transgenic ADT43 started showing visible yellowing symptoms at about $72 \mathrm{~h}$ after putting into the $\mathrm{NaCl}$ solution at which all the leaf discs of transgenic ADT43 remained green. Leaf discs of transgenic ADT43 started showing yellowing at $96 \mathrm{~h}$ after salinization $(100 \mathrm{mM}$ and $200 \mathrm{mM} \mathrm{NaCl})$ at which all the non-transgenic ADT43 discs turned completely yellow (Figure 7).

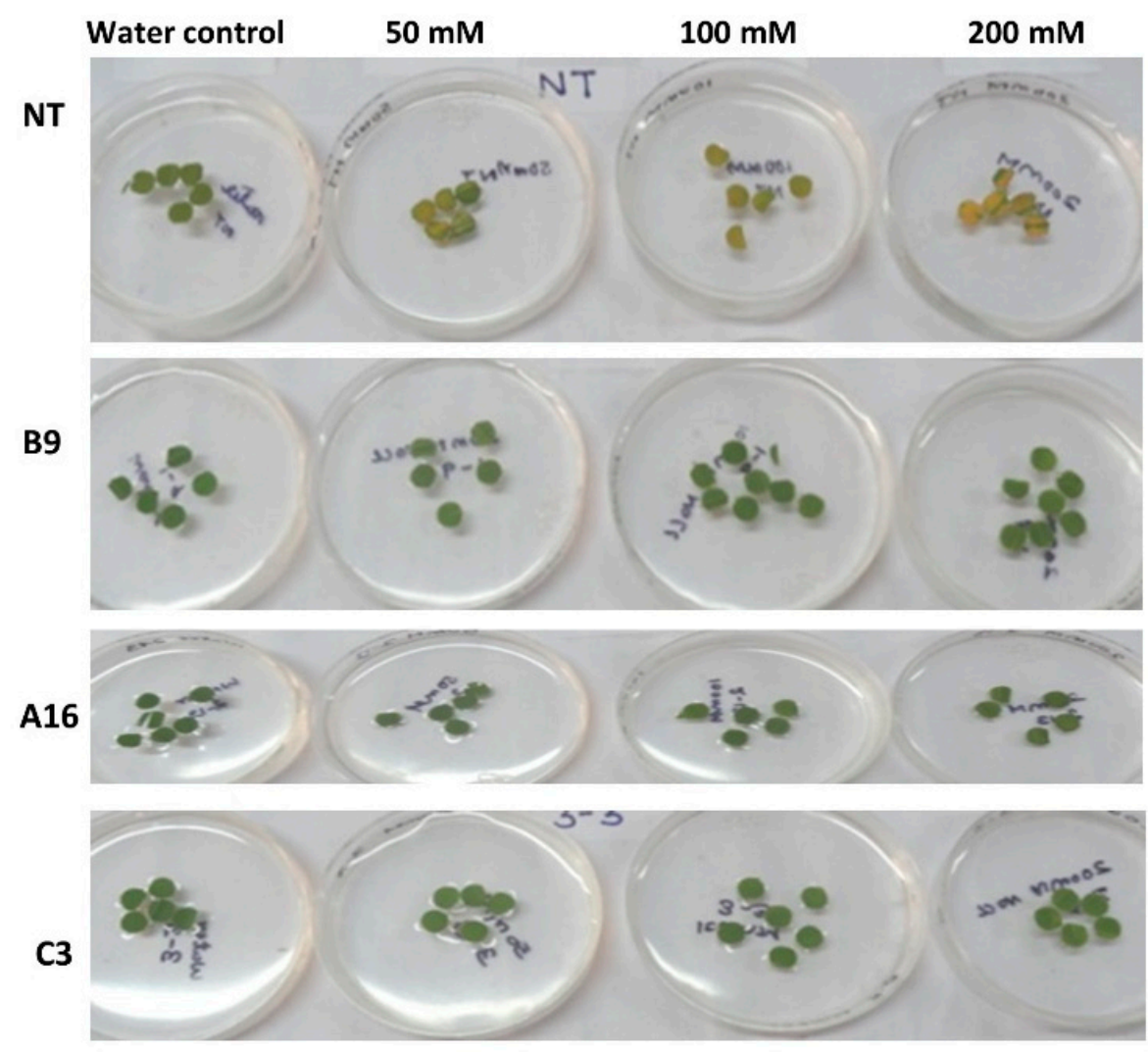

Figure 7. Chlorophyll stability assay in the leaf discs of non-transgenic (NT) and transgenic ADT 43 $\left(\mathrm{T}_{1}\right)$ lines at various levels of $\mathrm{NaCl}$ stress.

\subsection{Evaluation of $T_{2}$ and $T_{3}$ Progenies of Line \# A16 against Drought}

The transgenic line \#A16 possessing single copy integration and exhibiting a superior level of drought tolerance in $T_{1}$ generation was forwarded to $T_{2}$ and $T_{3}$ generation and evaluated for its responses against drought. On 12 DAIS, leaves of the transgenic line remained intact and green without any symptoms of leaf rolling and leaf drying (Figure 8a). Leaves of the transgenic line \# A16 maintained $72.69 \%$ RWC, whereas the non-transgenic ADT 43 retained only $56.28 \%$ of RWC (Figure 8c). The leaf temperature of the transgenic line was $24.82{ }^{\circ} \mathrm{C}$, whereas the non-transgenic plants registered $28.51{ }^{\circ} \mathrm{C}$. Non-transgenic plants showed an increase of $4-5^{\circ} \mathrm{C}$ during drought over its well-watered control, whereas the transgenic A16 showed an increase of only $1.63{ }^{\circ} \mathrm{C}$ over its control (Figure 8d). A similar drought response was exhibited by the transgenic line \# A16 in the $\mathrm{T}_{3}$ generation (Figure 8b,d). 


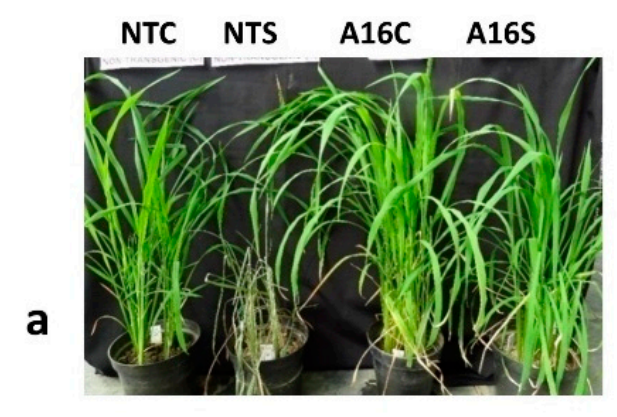

NTS NTC A16S A16C

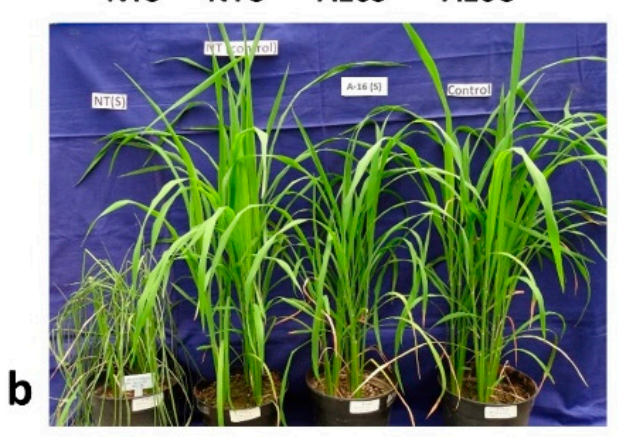

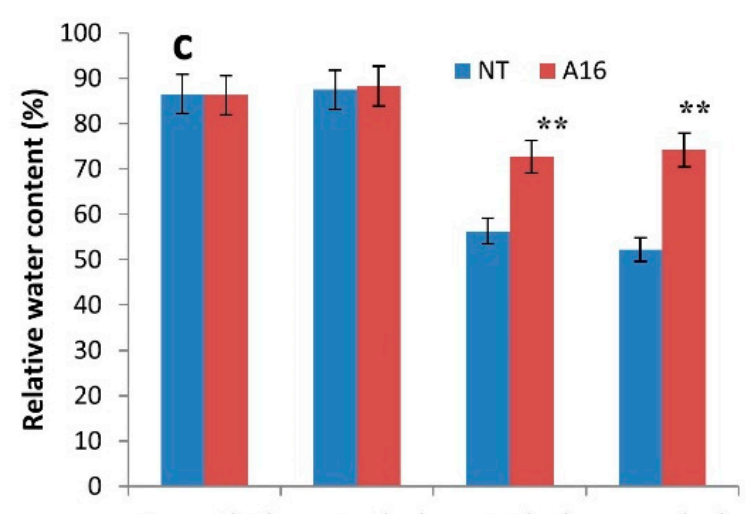

Control(T2) Control(T3) Stress(T2) Stress (T3)

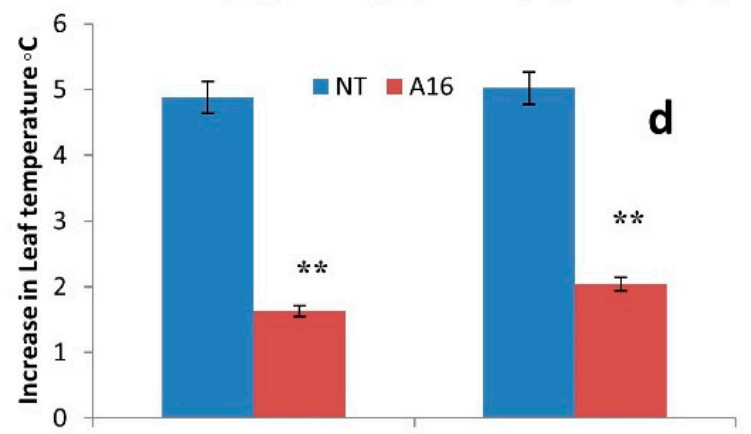

T2

T3

Figure 8. Responses of ADT 43 non-transgenic (NT) and transgenic (\# A16) line ( $\mathrm{T}_{2}$ and $\mathrm{T}_{3}$ progenies) to drought stress; (a) Performance of \# A16 ( $\left.\mathrm{T}_{2}\right)$ at 12 DAIS; (b) Performance of \# A16 ( $\left.\mathrm{T}_{3}\right)$ at 14 DAIS; NTC, Non-transgenic control; NTS, Non-transgenic stress; A16C, Control plants of \# A16; A16S, Stressed plants of \# A16; (c), Relative water content in the leaves of Non-transgenic and transgenic ADT 43; (d) increase in the leaf temperature of stressed plants over the respective controls; The values in the graph are the mean of three replications. ${ }^{* *}$ indicates statistical significance at $p<0.01$ (ANOVA compared to non-transgenic drought-stressed).

\subsection{Enhanced Salinity Tolerance of $A 16\left(T_{2}\right.$ and $\left.T_{3}\right)$ Progenies during Vegetative Stage Stress}

In $100 \mathrm{mM} \mathrm{NaCl}$ stress, the seedlings of non-transgenic ADT43 plants showed wilting of terminal leaves at 15 days after stress compared to the A16 progenies $\left(T_{2}\right)$, which were found to be healthy. After 45 days of salinity stress non-transgenic plants exhibited growth retardation and wilting of terminal leaves compared to the healthy A16 transgenic plants (Figure 9a). All the transgenic lines retained greenness in leaves and had higher root length than non-transgenic plants (Figure 9a). The non-transgenic ADT43 plants showed leaf chlorosis and leaf rolling symptoms after 30 days of salinity exposure at $100 \mathrm{mM} \mathrm{NaCl}$ stress, while the superior transgenic line A16 progenies $\left(\mathrm{T}_{3}\right)$ did not show any symptoms of salinity stress at this stage (Figure 9b). 

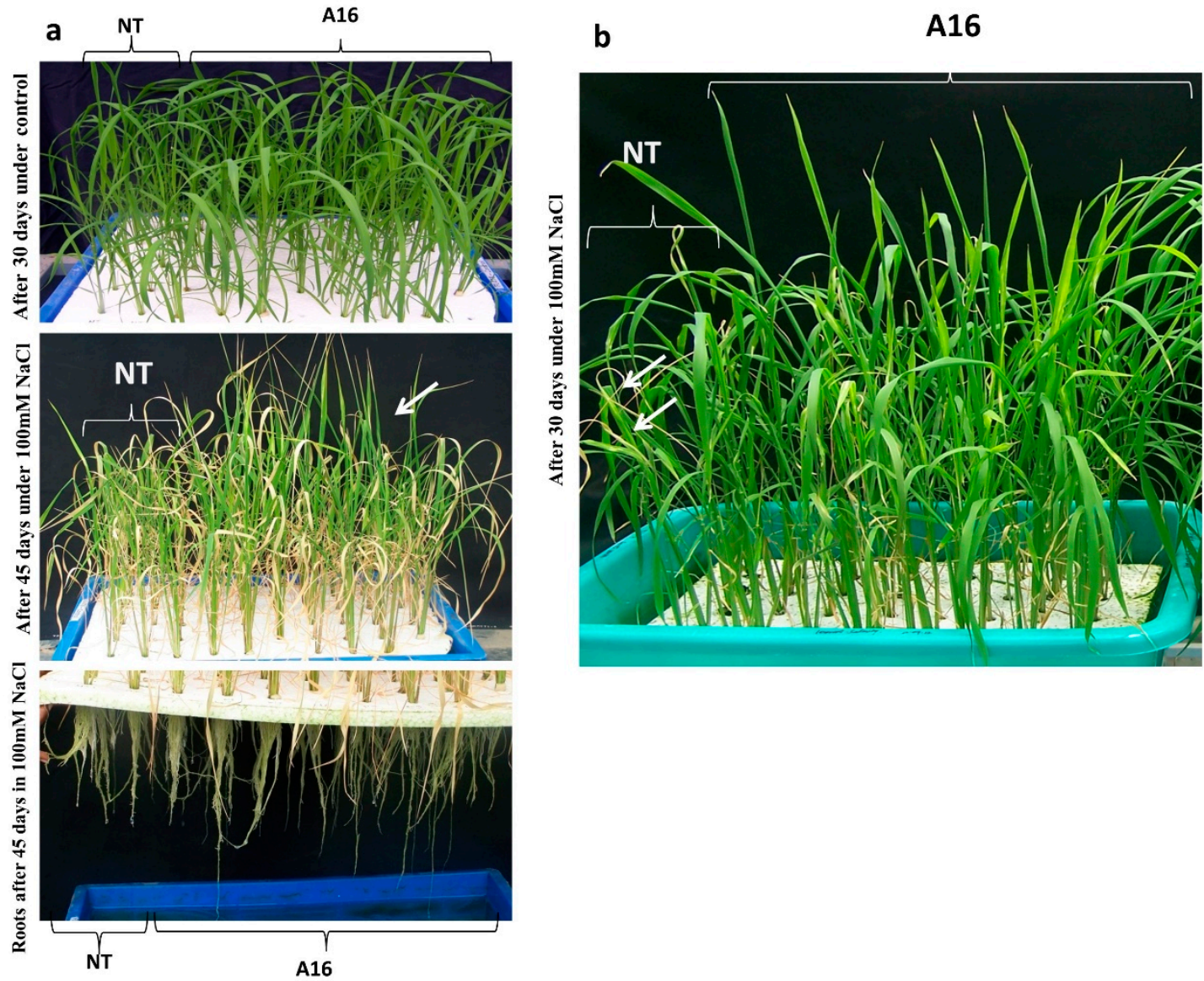

Figure 9. Responses of non-transgenic and transgenic ADT 43 (\# A16) seedlings to $100 \mathrm{mM} \mathrm{NaCl}$ stress; (a) Morphology of leaves and roots of transgenic $\left(\mathrm{T}_{2}\right)$ and non-transgenic ADT 43. White arrow indicates the erect leaves of A16 transgenic line; (b) Responses of transgenic ( $\mathrm{T}_{3}$ progenies of \# A16) at 30 DAIS. The white arrow indicates the leaf rolling and chlorosis symptoms in non-transgenic plants.

\subsection{Agronomic Evaluation of Transgenic ADT 43 under Drought}

The transgenic line A16 $\left(\mathrm{T}_{4}\right)$ was evaluated for its agronomic performance under well-watered and drought stress conditions in a transgenic screen house facility simulating field conditions (Figure 10a). Transgenic line \# A16 recorded a lesser reduction in the growth and yield traits during drought when compared to the non-transgenic ADT43. Under well-watered conditions, transgenic line \# A16 exhibited on par performance against its non-transgenic counterpart in its agronomic traits viz., plant height $(\mathrm{cm})$, number of tillers, panicle length $(\mathrm{cm})$, number of grains per panicle, grain yield per plant $(\mathrm{g})$, spikelet fertility (\%) and biomass per plant (g) (Table 1). Non-transgenic ADT 43 plants showed $22 \%$ reduction in the total number of spikelets per panicle during drought, whereas the transgenic plants showed only $2 \%$ reduction (Figure 10b). Non-transgenic plants showed $28 \%$ increase in their spikelet sterility, whereas A16 showed only $16 \%$ increase in its spikelet sterility (Table 1, Figure 10b). Transgenic line \# A16 did not show any significant yield reduction over its non-transgenic counterpart ADT 43 under normal conditions. Droughtinduced yield reduction was significantly higher in the non-transgenic ADT $43(74 \%)$ than the transgenic line \# A16 (57\%). (Table 1, Figure 10b). 
a
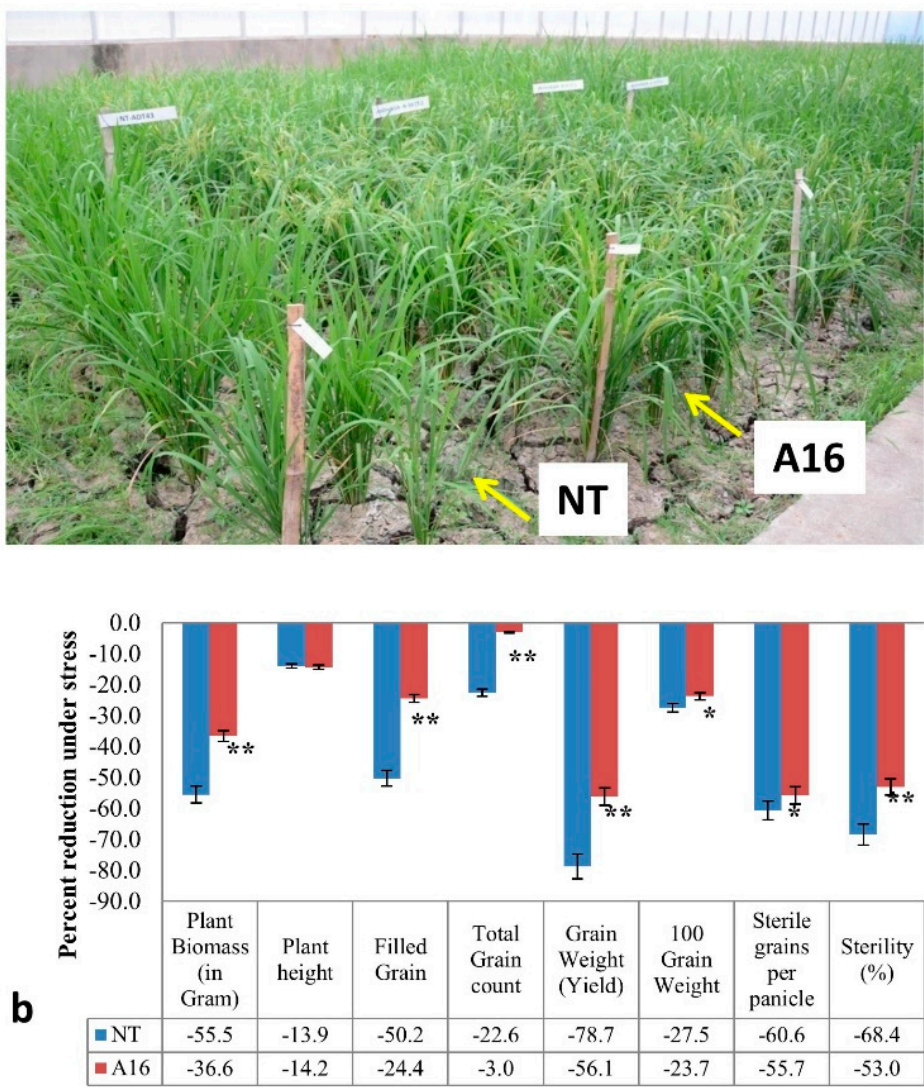

Figure 10. Performance of \# A16 under drought in the transgenic screen house facility. (a) Overall view of the performance of \# A16 over the non-transgenic ADT 43; (b) Percent reduction of various yield traits under drought stress. Values are mean of fifteen replications, ${ }^{* *}$ indicates statistical significance at $p<0.01$ and ${ }^{*}$ indicates significance at $p<0.05$ (ANOVA compared to non-transgenic drought-stressed lines).

Table 1. Agronomic performance of non-transgenic and transgenic ADT 43 ( $\mathrm{T}_{4}$ progenies of line \# A16) under normal and drought conditions. Values are mean \pm standard error of fifteen replications. Means with different alphabet letters are statistically significant using Fisher's Least Significant Difference.

\begin{tabular}{|c|c|c|c|c|c|c|}
\hline \multirow{2}{*}{ Traits } & \multicolumn{2}{|c|}{ NT } & \multicolumn{2}{|c|}{ A16 } & \multirow{2}{*}{$p$-Value } & \multirow{2}{*}{ LSD at $5 \%$} \\
\hline & Control & Stress & Control & Stress & & \\
\hline Plant height (cm) & $96.1 \pm 2.0^{\mathrm{A}}$ & $82.7 \pm 2.13^{B}$ & $97.9 \pm 1.40^{\mathrm{A}}$ & $83.95 \pm 1.12^{\mathrm{B}}$ & 0.001 & 6.428 \\
\hline No. of tillers per plant & $20.7 \pm 1.10^{\mathrm{A}}$ & $20.4 \pm 2.03^{\mathrm{A}}$ & $19.6 \pm 1.35^{\mathrm{A}}$ & $17.2 \pm 1.09^{C}$ & 0.01 & 2.456 \\
\hline No. of panicles per plant & $20.5 \pm 1.04^{\mathrm{A}}$ & $19 \pm 1.85^{\mathrm{A}}$ & $19.6 \pm 1.38^{\mathrm{A}}$ & $15.5 \pm 0.75^{\mathrm{B}}$ & 0.001 & 3.125 \\
\hline Plant Biomass (g) & $72.89 \pm 7.5^{\mathrm{A}}$ & $32.45 \pm 3.1^{C}$ & $70.16 \pm 2.9$ А В & $44.51 \pm 2.66^{\mathrm{BC}}$ & $<0.0001$ & 20.998 \\
\hline Panicle Length $(\mathrm{cm})$ & $20.87 \pm 0.40^{\mathrm{B}}$ & $16.97 \pm 0.35^{\mathrm{C}}$ & $21.99 \pm 0.22^{\mathrm{A}}$ & $22.155 \pm 0.34^{\mathrm{A}}$ & $<0.0001$ & 1.575 \\
\hline Number of spikelets per panicle & $199.5 \pm 10.8^{\mathrm{A}}$ & $154.5 \pm 11.30^{\mathrm{B}}$ & $201.9 \pm 16.90^{\mathrm{A}}$ & $195.78 \pm 7.0^{\mathrm{A}}$ & 0.0032 & 46.313 \\
\hline No. of filled spikelets & $176.5 \pm 11.3^{\mathrm{A}}$ & $87.89 \pm 8.1^{\mathrm{B}}$ & $177.66 \pm 15.60^{\mathrm{A}}$ & $134.35 \pm 6.70^{\mathrm{A}}$ & $<0.0001$ & 39.731 \\
\hline No. of sterile spikelets & $25.28 \pm 1.2^{\mathrm{B}}$ & $64.10 \pm 2.10^{\mathrm{A}}$ & $24.55 \pm 1.30^{\mathrm{B}}$ & $59.50 \pm 3.50^{\mathrm{A}}$ & 0.0001 & 22.204 \\
\hline Spikelet sterility (\%) & $13.02 \pm 1.10^{\mathrm{C}}$ & $41.25 \pm 4.1^{\mathrm{A}}$ & $14.50 \pm 1.20^{\mathrm{C}}$ & $30.88 \pm 2.4^{\mathrm{B}}$ & $<0.0001$ & 12.383 \\
\hline Grain yield per plant (g) & $44.24 \pm 4.5^{\mathrm{A}}$ & $9.42 \pm 3.1^{\mathrm{B}}$ & $43.73 \pm 1.7^{\mathrm{A}}$ & $19.18 \pm 1.2^{\mathrm{B}}$ & $<0.0001$ & 12.583 \\
\hline 100 Grain Weight $(\mathrm{g})$ & $1.6 \pm 0.03^{\mathrm{B}}$ & $1.16 \pm 0.02^{\mathrm{D}}$ & $1.78 \pm 0.02^{\mathrm{A}}$ & $1.36 \pm 0.02^{C}$ & $<0.0001$ & 0.1428 \\
\hline
\end{tabular}

\section{Discussion}

A sustained increase in rice production is facing serious threats from the increased occurrence of abiotic stresses like drought, salinity, flooding, and temperature extremes. Out of several abiotic stresses, drought and salinity remain at the top in affecting rice productivity. This is expected to be aggravated by the predicted effects of climate change. Several management practices viz., alternate wetting and drying (AWD) method of irri- 
gation and direct seeded rice (DSR) cultivation have shown better water use efficiency in rice cultivation [31]. However, non-availability of high yielding cultivars adapted to water-saving rice cultivation methods like AWD and DSR limits their widespread adoption. Developing drought and salinity tolerant rice cultivars seems to be a viable approach in achieving sustained increase in rice production under marginal environments and thereby to meet global demand. Conventional breeding has met with limited success in developing drought/salinity tolerant rice varieties as tolerance is controlled by complex mechanisms and lack of reliable phentoyping procedures. Marker-assisted breeding and genetic engineering enabled us to make substantial progress in developing drought/salinity tolerant rice varieties [32,33]. Under genetic engineering, one of the promising strategies is to modulate the expression levels of stress tolerance related TFs that might regulate a wide array of downstream genes/pathways and thus bringing the desired levels of tolerance to plants $[21,34]$. TFs play vital roles in modulating expression levels of genes involved in many biological processes such as development, growth, cell division, and responses to environmental stimulus [35].

Among the various transcription factors, MYB, NAC, bZIP, WRKY, and AP2/EREBP members play a major role in the ABA-dependent and $A B A$ independent signaling pathways controlling drought responses in plants [36]. The DREBs (dehydration responsive element binding) are members of the ERF family of transcription factors and regulate stress (cold, drought, temperature stress) responsive gene expression through the ABAindependent signal transduction pathway [29]. In Arabidopsis, DREBs/CBFs specifically interact with the dehydration responsive element/C repeat (DRE/CRT) cis-active elements, controlling the transcription of several stress-responsive genes [37]. The over-expression of DREB1A was found to enhance tolerance against drought in A. thaliana [29], tobacco [38], wheat [39], and potato [40]. Even though DREB1A was found to enhance tolerance against dehydration, its constitutive over-expression was associated with growth abnormalities and thereby leading to reduced yield. This was overcome by over-expressing the DREB1A under the control of a stress-inducible promoter rd29A, which reduced its undesirable effects on growth and development [29,30,41,42].

With the confidence gained from the above reports, attempts were made in this study to engineer drought tolerance in a popular rice variety ADT 43 through controlled overexpression of AtDREB1Adriven by a stress-inducible promoter $r d 29 A$. Transgenic ADT 43 lines exhibiting engineered expression of $A t D R E B 1 A$ driven by $r d 29 A$ promoter did not show any growth abnormalities when compared to non-transgenic ADT 43 (Table 1). The stress-inducible promoter $r d 29 A$ has been reported to minimize the adverse effects of growth retardation in Arabidopsis [30,43]. This study also recorded and reconfirmed the earlier observations.

Putative transgenic lines of ADT43 exhibiting controlled over-expression of AtDREB1A showed enhanced tolerance against drought. Transgenic lines of ADT 43 showed delayed rolling and wilting symptoms as against their wild type, which is in accordance with the earlier reports [44]. This may be due to the fact that the transgenic lines maintained higher internal water status at relatively equal level of moisture stress. Reduction in the relative water content (RWC) of leaves and stomatal closure are the two indicators of stress progression [45]. RWC is an index to measure the metabolic activity of tissues during dehydration and the level of tolerance against dehydration is positively correlated with RWC. In the present study, transgenic lines of ADT 43 engineered with AtDREB1A maintained relatively higher RWC as compared to its non-transgenic counterpart reflecting its greater degree of dehydration tolerance. Similar observations were recorded when AtDREB1A was over-expressed in groundnut and rice $[41,42,46]$. Loss of internal water and stomatal closure is associated with an increase in leaf temperature affecting cellular activities. Non-transgenic plants recorded an increase of about $8^{\circ} \mathrm{C}$ at 18 DAIS as compared to their well-watered controls, whereas transgenic lines showed an increase of only $2-3^{\circ} \mathrm{C}$ against their controls (Figure $3 b$ ). This increase in leaf temperature may be associated with stomatal closure and reduced transpiration (Figure 3a,b). Transgenic lines of ADT 43 were able to 
maintain their stomata under partially closed conditions and thus maintain minimum level of transpiration to cool the canopy and thereby reduce the canopy/leaf temperature. Such an increase in leaf temperature during dehydration due to increased respiration and decreased transpiration has been reported earlier [43]. DREB1A was reported to alter the metabolism of osmoprotectants like proline and sugar accumulation during dehydration, thereby leading to enhanced tolerance [47]. Enhanced dehydration tolerance of transgenic ADT 43 through maintenance of higher RWC \% and partially opened stomata may be due to the better turgor maintenance involving accumulation osmoprotectants.

$D R E B 1 A$ is known to be induced by salinity, drought, and low temperature $[21,24,43]$. Transgenic line of ADT 43 engineered with AtDREB1A showed increased tolerance to salinity $(\mathrm{NaCl})$ in terms of germination (Figure $5 \mathrm{a}$ ) and retention of chlorophyll (Figure 7). Reduced rate of degradation of chlorophyll exhibited by transgenic plants over-expressing DREB1A through preventing the photo-oxidation and degradation of chlorophyll has already been reported $[42,48,49]$.

Effect of any QTL/gene(s) involved in drought tolerance can be precisely estimated based on the agronomic performance and yield of NILs introgressed with target QTLs or transgenic plants over-expressing putative candidate gene(s). Out of several experiments demonstrating the influence of putative candidate genes on drought tolerance in rice [5,8,44,50-53], only very few transgenic rice exhibiting enhanced tolerance has been taken to the field evaluation. This may be due to the fact that the majority of the reports involving the development of drought-tolerant rice through transgenic method have been carried out under controlled laboratory conditions at the seedling stage or in pot culture experiments containing a limited volume of soil. Only a very few attempts have been made to demonstrate the effects of transgenes on rice yield under field drought conditions [54-58]. A major breakthrough in the development of drought-tolerant rice cultivars through conventional/molecular breeding was achieved during recent years when the yield was considered as a direct selection criteria under well-watered and drought conditions [59]. This warrants the development or adoption of a similar strategy of evaluating transgenic plants under field or near field conditions for yield under stress. In this study, transgenic lines of ADT 43 were evaluated under a controlled transgenic screen house facility simulating field conditions along with non-transgenic ADT 43 (Figure 10a). Transgenic lines subjected to drought by withholding irrigation from 65th day after sowing onwards did not show any growth abnormalities or yield penalty when compared to its wild type under well-watered conditions as demonstrated earlier [29]. Non-transgenic ADT 43 showed 74\% yield reduction under drought, whereas the transgenic ADT 43 line (\# A16) showed 15-20\% yield advantage over ADT 43. This increased yield reduction in the non-transgenic ADT 43 may be attributed to increased spikelet sterility (28\%). This may be again due to rapid loss of water in the non-transgenic ADT 43, as evident from its lower RWC\% and reduction in the associated cellular metabolic activities. The strong up-regulation of $A t D R E B 1 A$ in transgenic lines during dehydration showed the effectiveness of $r d 29 A$ promoter in controlling the expression of transgene during dehydration, as reported earlier [60]. Through the overall co-ordinated regulation of stomatal control, reduced water loss, and cellular turgor maintenance, transgenic lines of ADT 43 performed better than their non-transgenic counterparts.

\section{Materials and Methods}

\subsection{Construction of Plant Transformation Vector-Harboring AtDREB1A}

A cDNA encoding for DREB1A was isolated from Arabidopsis thaliana based on the nucleotide sequence information available at NCBI (EF523124) and cloned in a plant transformation vector pCAMBIA1300 under the control of a stress-inducible promoter $r d 29 \mathrm{~A}$ and a selectable marker encoding for hygromycin $(h p t)$ resistance (obtained as a kind gift from Dr. M. Parani, Head, Dept. of Genetic Engineering, SRM University, Chennai). This plasmid was then introduced into Agrobacterium tumefaciens strain LBA4404 by triparental mating and used for genetic transformation of a popular but drought susceptible rice 
variety ADT43 through Agrobacterium-mediated transformation [61,62]. Embryogenic calli were obtained from 14 day-old immature embryos of ADT43 and co-cultivated with the Agrobacterium strain LBA4404 harboring pCAMBIA1300 engineered with AtDREB1A. Putatively transformed calli were selected in a medium containing $50 \mathrm{~g} / \mathrm{mL}$ hygromycin. After two cycles (10 days of the first selection and 7 days of second selection) of selection, resistant calli were transferred to the regeneration medium. Regenerated plantlets (shoots) with well-established roots were hardened and maintained under transgenic greenhouse conditions.

\subsection{Molecular Characterization of Putative Transgenic ADT43 Lines Engineered with AtDREB1A} PCR Analysis and Southern Hybridization Analysis

Genomic DNA was extracted from the leaves of putative transgenic plants by using modified CTAB method $[63,64]$. Primers specific to hygromycin phosphotransferase $(h p t)$ (Forward: 5'AGAAGAAGATGTTGGCGACCT3' AGCTG3') and AtDREB1A (Forward: 5'CGAGTCTTCGGTTTCCTCA3'; Reverse: 5'ACTGTACGGACGGAAGCGGC3') were used for screening the putative transgenic plants along with non-transgenic ADT 43 using PCR. PCR amplification using hpt primers was performed by following conditions viz., $94{ }^{\circ} \mathrm{C}$ for $5 \mathrm{~min}$; 30 cycles of $94{ }^{\circ} \mathrm{C}$ for $1 \mathrm{~min}, 55^{\circ} \mathrm{C}$ for $1 \mathrm{~min}, 72{ }^{\circ} \mathrm{C}$ for $1 \mathrm{~min}$; finally, at $72{ }^{\circ} \mathrm{C}$ for $5 \mathrm{~min}$. PCR amplification using gene-specific (AtDREB1A) primers was carried out at $94^{\circ} \mathrm{C}$ for 5 min leading to 35 cycles of amplification (denaturation at $94{ }^{\circ} \mathrm{C}$ for $1 \mathrm{~min}$, annealing at $56^{\circ} \mathrm{C}$ for $1 \mathrm{~min}$ and extension at $72{ }^{\circ} \mathrm{C}$ for $1 \mathrm{~min}$ ) followed by a final extension at $72{ }^{\circ} \mathrm{C}$ for $10 \mathrm{~min}$.

Copy number of the transgene $(A t D R E B 1 A)$ was determined by southern hybridization analysis using the hpt gene as a probe. About $25 \mu \mathrm{g}$ of genomic DNA from each sample was digested with $\mathrm{BamH1}$, fractionated on $0.8 \%$ agarose gel transferred to a nylon membrane (Hybond-N+; Amersham, Sigma Aldrich, Chennai, India) by alkaline transfer [65] and baked at $80^{\circ} \mathrm{C}$ for $1 \mathrm{~h}$. The probe was labeled by using Random Primer labeling kit (M/s. Bangalore Genei Pvt. Ltd., Bangalore, India) and the radiolabeled $\mathrm{P}^{32}$ probe was denatured and hybridized to the membrane at $42{ }^{\circ} \mathrm{C}$. After $16 \mathrm{~h}$ of hybridization, the blots were washed with $1 \times X$ SSC, $0.5 \%$ SDS $(w / v)$ at $42{ }^{\circ} \mathrm{C}$ for $15 \mathrm{~min}$ and exposed to X-ray film (KODAK) for $24 \mathrm{~h}$ and auto-radiographed.

\subsection{Evaluation of Transgenic ADT43 Lines Engineered with AtDREB1A against Drought}

Transgenic ADT43 lines $\left(\mathrm{T}_{1}\right)$ were evaluated for their performance against drought along with its non-transgenic counterpart ADT43. A superior single copy transgenic event (\# A16) was forwarded up to $\mathrm{T}_{4}$ generation through selfing. Line \# A16 was evaluated for the inheritance of transgene and drought tolerance in $T_{2}$ and $T_{3}$ progenies. Non-transgenic and transgenic ADT43 plants were grown up to ten weeks, and one set of plants were subjected to water stress by withholding irrigation. Before withholding irrigation, all the pots were equilibrated by irrigating up to field capacity.

\subsubsection{Measurement Soil and Leaf Water Status}

Progression of drought stress was monitored by measuring relative water content (RWC) in the leaves of control and drought-stressed plants of non-transgenic and transgenic ADT43 [66]. Soil moisture content was measured using the gravimetric method [67]. For measuring RWC, fresh weight of three leaf segments of third leaf (10-15 cm length) collected from control and drought-stressed plants of transgenic and non-transgenic ADT43 were recorded and leaves were put into screw cap tubes containing water by keeping the lower end of leaves in water. Turgid weight of leaf segments was recorded after 5-6 h and leaves were dried at $65^{\circ} \mathrm{C}$ for $48 \mathrm{~h}$ before recording the dry weight. RWC was calculated as follows:

$$
\operatorname{RWC}(\%)=\frac{(\text { Fresh weight }- \text { Dry weight })}{(\text { Turgid weight }- \text { Dry weight }))} \times 100
$$




\subsubsection{Measurement of Leaf Temperature}

Tissue temperature in the leaves of control and drought-stressed plants of transgenic and non-transgenic ADT 43 was measured using an infra-red gun (Model APOGE MI200). IR thermometer was held at a right angle so that the sensor viewed only the leaf surface and thus preventing the thermometer from sensing the soil surface. Three temperature readings were recorded for each plant.

\subsubsection{Monitoring Drought-Responsive Stomatal Behavior in the Transgenic and} Non-Transgenic ADT 43

Drought responsive stomatal behavior was studied in the drought-stressed leaves of a transgenic (Event \# A16) and non-transgenic ADT $43\left(\mathrm{~T}_{1}\right)$ using Scanning Electron Microscope (FEI Quanta 250, Icon analytical, Mumbai, India). Leaves were collected from the drought-stressed (18 days after imposing stress (DAIS) plants of transgenic line \# A16 and non-transgenic ADT 43 line and used for SEM analysis. Leaf samples were mounted on round aluminum stubs with the aid of double side adhesive tape, and the adaxial surface of leaf samples was scanned and photographed.

\subsection{Measuring Transcript Abundance of AtDREB1A through RT-PCR}

Leaf tissues collected from the control and drought-stressed plants of transgenic lines and non-transgenic ADT $43\left(\mathrm{~T}_{1}\right)$ was used for profiling the expression of AtDREB1A through qRT-PCR. Total RNA was isolated from leaf tissues using Trizol reagent (Biobasic, Alberta, Canada). An equal amount of DNAse treated total RNA (about $1 \mu \mathrm{g}$ ) was converted into sscDNA using Transcriptor High Fidelity cDNA Synthesis Kit (M/s. Roche, Germany) and used for qRT-PCR analysis using StepOne Plus qPCR (M/s. Applied Biosystems, ABI, Chennai, India) by following default cycling conditions $\left(10 \mathrm{~min} 95^{\circ} \mathrm{C}, 40\right.$ cycles of $15 \mathrm{~s}$ at $95^{\circ} \mathrm{C}$ and $60 \mathrm{~s}$ at $60^{\circ} \mathrm{C}$ ). The reaction mixture contained SYBR Green Master mix (Roche Diagnostics, Roche, Chennai, India) $300 \mathrm{nM}$ of AtDREB1A gene-specific primers and $2 \mu \mathrm{L}$ of diluted cDNA (1:10) in each $15 \mu \mathrm{L}$ reaction. Blank controls containing all ingredients of the RT-PCR reaction except the cDNA template were also maintained. The abundance (relative quantity) of mRNAs, was calculated using the comparative $\mathrm{Ct}(\Delta \Delta \mathrm{Ct}$ method) [68]. An adequate number of biological replications (three replications) was used and each biological replication was repeated three times. Ubiquitin was used as an endogenous reference gene for the normalization of $\mathrm{Ct}$ values.

\subsection{Evaluation of Transgenic ADT43 Lines against Salinity}

\subsubsection{Germination Ability}

Transgenic lines $\left(T_{1}\right)$ were evaluated for their ability to germinate under salinity. Seeds of transgenic and non-transgenic ADT 43 were germinated in different concentrations of $\mathrm{NaCl}$ solutions (50, 100 and $200 \mathrm{mM} \mathrm{NaCl})$. Fifteen seeds in each line were germinated in Petri dishes containing different concentrations of $\mathrm{NaCl}$ and kept at $24 \pm 1{ }^{\circ} \mathrm{C}$ along with suitable controls (water). The number of germinated seeds was recorded at every $24 \mathrm{~h}$ interval for 9 days. Germination percentage was scored on 8 DAS. Observations on the number of germinated seeds, shoot length $(\mathrm{cm})$ and root length $(\mathrm{cm})$ were recorded and used for calculating the vigor index of seedlings grown under control and salinity conditions. Germination percentage was calculated by using the formula as described by [69].

$$
\text { Germination \% }=\frac{\text { No.of germinated seeds }}{\text { No.of seeds sown }} \times 100
$$

\subsubsection{Chlorophyll Retention Capacity under Salinity}

Leaf discs from three months old transgene positive plants were excised from the leaves of both transgenic and non-transgenic plants $\left(\mathrm{T}_{1}\right)$ of ADT 43. Excised leaf discs were floated on solutions containing various concentrations of $\mathrm{NaCl}(50 \mathrm{mM}, 100 \mathrm{mM}, 200 \mathrm{mM}$ 
$\mathrm{NaCl}$ ) along with a control (water). Depletion of chlorophyll (yellowing of leaf discs) was assessed regularly and photographed.

\subsubsection{Salinity Tolerance during the Vegetative Phase}

The $\mathrm{T}_{2}$ and $\mathrm{T}_{3}$ progenies of superior single copy transgenic event (\#A16) were evaluated for their salinity tolerance during vegetative stage along with the non-transgenic lines. Seeds of both non-transgenic and transgenic lines were germinated in petri plates (up to 7 days) and then PCR positive transgenic plants were transferred to a hydroponics system in trays filled with Yoshida solution. The plants were grown under Yoshida solution for 35 days and salinity stress was imposed by adding $100 \mathrm{mM} \mathrm{NaCl}$ to the Yoshida solution. Effect of salinity stress on both transgenic and non-transgenic plants was assessed based on the development of wilting and drying of leaves.

\subsection{Agronomic Evaluation of Transgenic Lines under Transgenic Screen House Conditions}

$\mathrm{T}_{4}$ progenies were evaluated for their agronomic performance under irrigated and drought conditions against its non-transgenic counterpart ADT43. Twenty-five old seedlings of transgenic and non-transgenic ADT43 were planted $(20 \times 20 \mathrm{~cm})$ in transgenic screen house facility. Standard practices of fertilizer application (100; 50; $50 \mathrm{Kg}$ of N, P and K per ha), irrigation and weeding were followed till 40 days after transplanting. Plants were grown under well-watered conditions up to 40 days and a set of plants were subjected to drought by withholding irrigation by maintaining appropriate well-watered control plots. Stressed plots were left without irrigation till maturity and harvest (110 days after sowing). Observations on soil moisture, RWC \%, plant height, number of tillers, days to flowering, panicle length, number of grains per panicle, spikelet fertility, hundred grain weight, grain yield per plant and biomass per plant were recorded in both well-watered and drought-stressed plants.

\subsection{Statistical Analyses}

Experimental data were statistically analyzed using analysis of variance (ANOVA) and the multiple comparisons were carried out using Fisher's Least Significant Difference (LSD) test. All the statistical analyses were carried out using Statistical Analysis System package (SAS 9.2).

\section{Conclusions}

Over-expression of the transcription factors regulating activation of a cascade of stress-responsive downstream genes seems to be a promising strategy in developing stresstolerant crop varieties. In this study, transgenic lines of a popular rice variety ADT 43 engineered for controlled expression of AtDREB1A were developed and demonstrated for their enhanced tolerance to drought and salinity. Transgenic rice lines were found to exhibit stronger induction of AtDREB1A transcripts during the drought when compared to non-transgenic ADT43. The transgenic line \# A16 $\left(\mathrm{T}_{4}\right.$ generation) was demonstrated for the stable inheritance of the transgene AtDREB1A and enhanced drought tolerance under simulated field conditions. Transgenic ADT43 engineered with AtDREB1A exhibiting enhanced tolerance to drought could be a valuable genetic material to grow under waterlimiting and saline conditions.

Author Contributions: R.M. and V.R. were involved in the design and conduct of experiments and manuscript preparation; A.B.S., S.M.P. and C.N.S. were involved in the generation of the transgenic rice lines and the characterization of the transgenic lines; H.R., R.K., J.N. and S.T. were involved in the evaluation of transgenic lines under drought; P.M. was involved in the cloning and construction of vector and helped in revising the manuscript. All authors have read and agreed to the published version of the manuscript.

Funding: This research was funded by Department of Biotechnology, Government of India, New Delhi (Grant Number BT/PR13454/COE/34/43/2015). 
Institutional Review Board Statement: Not Applicable.

Informed Consent Statement: Not Applicable.

Data Availability Statement: Data is contained within the article.

Acknowledgments: The authors are grateful to the Department of Biotechnology, Government of India, New Delhi for providing financial support (Grant Number BT/PR13454/COE/34/43/2015).

Conflicts of Interest: The authors declare no competing interests.

\section{References}

1. Cooper, P.; Dimes, J.; Rao, K.; Shapiro, B.; Shiferaw, B.; Twomlow, S. Coping better with current climatic variability in the rain-fed farming systems of sub-Saharan Africa: An essential first step in adapting to future climate change? Agric. Ecosyst. Environ. 2008, 126, 24-35. [CrossRef]

2. Iba, K. Acclimative response to temperature stress in higher plants: Approaches of gene engineering for temperature tolerance. Annu. Rev. Plant Biol. 2002, 53, 225-245. [CrossRef] [PubMed]

3. Zhu, J.-K. Salt and drought stress signal transduction in plants. Annu. Rev. Plant Biol. 2002, 53, 247-273. [CrossRef] [PubMed]

4. Yamaguchi-Shinozaki, K.; Shinozaki, K. Transcriptional regulatory networks in cellular responses and tolerance to dehydration and cold stresses. Annu. Rev. Plant Biol. 2006, 57, 781-803. [CrossRef]

5. Hirayama, T.; Shinozaki, K. Research on plant abiotic stress responses in the post-genome era: Past, present and future. Plant J. 2010, 61, 1041-1052. [CrossRef]

6. Matsukura, S.; Mizoi, J.; Yoshida, T.; Todaka, D.; Ito, Y.; Maruyama, K.; Shinozaki, K.; Yamaguchi-Shinozaki, K. Comprehensive analysis of rice DREB2-type genes that encode transcription factors involved in the expression of abiotic stress-responsive genes. Mol. Genet. Genom. 2010, 283, 185-196. [CrossRef]

7. Lata, C.; Prasad, M. Role of DREBs in regulation of abiotic stress responses in plants. J. Exp. Bot. 2011, 62, 4731-4748. [CrossRef]

8. Shinozaki, K.; Yamaguchi-Shinozaki, K. Gene networks involved in drought stress response and tolerance. J. Exp. Bot. 2007, 58, 221-227. [CrossRef]

9. Golldack, D.; Lüking, I.; Yang, O. Plant tolerance to drought and salinity: Stress regulating transcription factors and their functional significance in the cellular transcriptional network. Plant Cell Rep. 2011, 30, 1383-1391. [CrossRef]

10. Nakashima, K.; Yamaguchi-Shinozaki, K.; Shinozaki, K. The transcriptional regulatory network in the drought response and its crosstalk in abiotic stress responses including drought, cold, and heat. Front. Plant Sci. 2014, 5, 170. [CrossRef]

11. Chen, L.; Song, Y.; Li, S.; Zhang, L.; Zou, C.; Yu, D. The role of WRKY transcription factors in plant abiotic stresses. Biochim. Biophys. Acta (BBA)-Gene Regul. Mech. 2012, 1819, 120-128. [CrossRef]

12. Nuruzzaman, M.; Sharoni, A.M.; Kikuchi, S. Roles of NAC transcription factors in the regulation of biotic and abiotic stress responses in plants. Front. Microbiol. 2013, 4, 248. [PubMed]

13. Guan, Y.; Meng, X.; Khanna, R.; LaMontagne, E.; Liu, Y.; Zhang, S. Phosphorylation of a WRKY transcription factor by MAPKs is required for pollen development and function in Arabidopsis. PLoS Genet 2014, 10, e1004384. [CrossRef] [PubMed]

14. Dietz, K.-J.; Vogel, M.O.; Viehhauser, A. AP2/EREBP transcription factors are part of gene regulatory networks and integrate metabolic, hormonal and environmental signals in stress acclimation and retrograde signalling. Protoplasma 2010, 245, 3-14. [PubMed]

15. Mizoi, J.; Shinozaki, K.; Yamaguchi-Shinozaki, K. AP2/ERF family transcription factors in plant abiotic stress responses. Biochim. Biophys. Acta (BBA)-Gene Regul. Mech. 2012, 1819, 86-96.

16. Chandler, J.W. Class VIIIb APETALA2 ethylene response factors in plant development. Trends Plant Sci. 2018, $23,151-162$. [CrossRef] [PubMed]

17. Hussain, S.; Iqbal, M.; Arif, M.; Amjad, M. Beyond osmolytes and transcription factors: Drought tolerance in plants via protective proteins and aquaporins. Biol. Plant. 2011, 55, 401-413.

18. Xie, Z.; Nolan, T.M.; Jiang, H.; Yin, Y. AP2/ERF transcription factor regulatory networks in hormone and abiotic stress responses in Arabidopsis. Front. Plant Sci. 2019, 10, 228.

19. Yamaguchi-Shinozaki, K.; Shinozaki, K. Arabidopsis DNA encoding two desiccation-responsive rd29 genes. Plant Physiol. 1993, 101, 1119. [CrossRef]

20. Stockinger, E.J.; Gilmour, S.J.; Thomashow, M.F. Arabidopsis thaliana CBF1 encodes an AP2 domain-containing transcriptional activator that binds to the C-repeat/DRE, a cis-acting DNA regulatory element that stimulates transcription in response to low temperature and water deficit. Proce. Natl. Acad. Sci. USA 1997, 94, 1035-1040.

21. Liu, Q.; Kasuga, M.; Sakuma, Y.; Abe, H.; Miura, S.; Yamaguchi-Shinozaki, K.; Shinozaki, K. Two transcription factors, DREB1 and DREB2, with an EREBP/AP2 DNA binding domain separate two cellular signal transduction pathways in drought-and low-temperature-responsive gene expression, respectively, in Arabidopsis. Plant Cell 1998, 10, 1391-1406. [PubMed]

22. Yamaguchi-Shinozaki, K.; Shinozaki, K. Organization of cis-acting regulatory elements in osmotic-and cold-stress-responsive promoters. Trends Plant Sci. 2005, 10, 88-94. [CrossRef] [PubMed]

23. Dubouzet, J.G.; Sakuma, Y.; Ito, Y.; Kasuga, M.; Dubouzet, E.G.; Miura, S.; Seki, M.; Shinozaki, K.; Yamaguchi-Shinozaki, K. OsDREB genes in rice, Oryza sativa L., encode transcription activators that function in drought-, high-salt-and cold-responsive gene expression. Plant J. 2003, 33, 751-763. [CrossRef] [PubMed] 
24. Gilmour, S.J.; Sebolt, A.M.; Salazar, M.P.; Everard, J.D.; Thomashow, M.F. Overexpression of the Arabidopsis CBF3transcriptional activator mimics multiple biochemical changes associated with cold acclimation. Plant Physiol. 2000, 124, 1854-1865. [CrossRef] [PubMed]

25. Maruyama, K.; Sakuma, Y.; Kasuga, M.; Ito, Y.; Seki, M.; Goda, H.; Shimada, Y.; Yoshida, S.; Shinozaki, K.; Yamaguchi-Shinozaki, K. Identification of cold-inducible downstream genes of the Arabidopsis DREB1A/CBF3 transcriptional factor using two microarray systems. Plant J. 2004, 38, 982-993. [CrossRef] [PubMed]

26. Wang, Q.; Guan, Y.; Wu, Y.; Chen, H.; Chen, F.; Chu, C. Overexpression of a rice OsDREB1F gene increases salt, drought, and low temperature tolerance in both Arabidopsis and rice. Plant Mol. Biol. 2008, 67, 589-602. [CrossRef] [PubMed]

27. Cong, L.; Zheng, H.-C.; Zhang, Y.-X.; Chai, T.-Y. Arabidopsis DREB1A confers high salinity tolerance and regulates the expression of GA dioxygenases in Tobacco. Plant Sci. 2008, 174, 156-164. [CrossRef]

28. Hong, B.; Tong, Z.; Ma, N.; Li, J.; Kasuga, M.; Yamaguchi-Shinozaki, K.; Gao, J. Heterologous expression of the AtDREB1A gene in chrysanthemum increases drought and salt stress tolerance. Sci. China Ser. C Life Sci. 2006, 49, 436-445. [CrossRef]

29. Kasuga, M.; Liu, Q.; Miura, S.; Yamaguchi-Shinozaki, K.; Shinozaki, K. Improving plant drought, salt, and freezing tolerance by gene transfer of a single stress-inducible transcription factor. Nat. Biotechnol. 1999, 17, 287-291. [CrossRef]

30. Ganguly, M.; Roychoudhury, A.; Sarkar, S.N.; Sengupta, D.N.; Datta, S.K.; Datta, K. Inducibility of three salinity/abscisic acid-regulated promoters in transgenic rice with gusA reporter gene. Plant Cell Rep. 2011, 30, 1617. [CrossRef]

31. Acosta-Motos, J.R.; Rothwell, S.A.; Massam, M.J.; Albacete, A.; Zhang, H.; Dodd, I.C. Alternate wetting and drying irrigation increases water and phosphorus use efficiency independent of substrate phosphorus status of vegetative rice plants. Plant Physiol. Biochem. 2020, 155, 914-926. [CrossRef] [PubMed]

32. Rahman, H.; Ramanathan, V.; Nallathambi, J.; Duraialagaraja, S.; Muthurajan, R. Over-expression of a NAC 67 transcription factor from finger millet (Eleusine coracana L.) confers tolerance against salinity and drought stress in rice. BMC Biotechnol. 2016, 16, 35. [CrossRef] [PubMed]

33. Valarmathi, M.; Sasikala, R.; Rahman, H.; Jagadeeshselvam, N.; Kambale, R.; Raveendran, M. Development of salinity tolerant version of a popular rice variety improved white ponni through marker assisted back cross breeding. Plant Physiol. Rep. 2019, 24, 262-271. [CrossRef]

34. Jaglo-Ottosen, K.R.; Gilmour, S.J.; Zarka, D.G.; Schabenberger, O.; Thomashow, M.F. Arabidopsis CBF1 overexpression induces COR genes and enhances freezing tolerance. Science 1998, 280, 104-106. [CrossRef] [PubMed]

35. Ramanjulu, S.; Bartels, D. Drought-and desiccation-induced modulation of gene expression in plants. Plant Cell Environ. 2002, 25, 141-151. [CrossRef] [PubMed]

36. Xin, L.; Yun, L. Transcription Factors Re1ated to Plant Stress-To1erance. Chin. Agric. Sci. Bull. 2006, 4, 61-65.

37. Seki, M.; Narusaka, M.; Abe, H.; Kasuga, M.; Yamaguchi-Shinozaki, K.; Carninci, P.; Hayashizaki, Y.; Shinozaki, K. Monitoring the expression pattern of 1300 Arabidopsis genes under drought and cold stresses by using a full-length cDNA microarray. Plant Cell 2001, 13, 61-72.

38. Kasuga, M.; Miura, S.; Shinozaki, K.; Yamaguchi-Shinozaki, K. A combination of the Arabidopsis DREB1A gene and stressinducible rd29A promoter improved drought-and low-temperature stress tolerance in tobacco by gene transfer. Plant Cell Physiol. 2004, 45, 346-350. [CrossRef]

39. Khan, S.; Anwar, S.; Yu, S.; Sun, M.; Yang, Z.; Gao, Z.-q. Development of drought-tolerant transgenic wheat: Achievements and limitations. Int. J. Mol. Sci. 2019, 20, 3350. [CrossRef]

40. Jia, X.; Li, Y.; Qi, E.; Ma, S.; Hu, X.; Wen, G.; Wang, Y.; Li, J.; Zhang, X.; Wang, H. Overexpression of the Arabidopsis DREB1A gene enhances potato drought-resistance. Russ. J. Plant Physiol. 2016, 63, 523-531. [CrossRef]

41. Datta, K.; Baisakh, N.; Ganguly, M.; Krishnan, S.; Yamaguchi Shinozaki, K.; Datta, S.K. Overexpression of Arabidopsis and rice stress genes' inducible transcription factor confers drought and salinity tolerance to rice. Plant Biotechnol. J. 2012, 10, 579-586. [CrossRef] [PubMed]

42. Ravikumar, G.; Manimaran, P.; Voleti, S.; Subrahmanyam, D.; Sundaram, R.; Bansal, K.; Viraktamath, B.; Balachandran, S. Stress-inducible expression of AtDREB1A transcription factor greatly improves drought stress tolerance in transgenic indica rice. Transgenic Res. 2014, 23, 421-439. [CrossRef] [PubMed]

43. Siddique, M.; Hamid, A.; Islam, M. Drought stress effects on water relations of wheat. Bot. Bull. Acad. Sin. 2000, 41, 35-39.

44. Bhatnagar-Mathur, P.; Vadez, V.; Sharma, K.K. Transgenic approaches for abiotic stress tolerance in plants: Retrospect and prospects. Plant Cell Rep. 2008, 27, 411-424. [CrossRef] [PubMed]

45. Gerakis, P.; Guerrero, F; Williams, W. Growth, water relations and nutrition of three grassland annuals as affected by drought. J. Appl. Ecol. 1975, 12, 125-135. [CrossRef]

46. Bhatnagar-Mathur, P.; Devi, M.J.; Reddy, D.S.; Lavanya, M.; Vadez, V.; Serraj, R.; Yamaguchi-Shinozaki, K.; Sharma, K.K. Stress-inducible expression of At DREB1A in transgenic peanut (Arachis hypogaea L.) increases transpiration efficiency under water-limiting conditions. Plant Cell Rep. 2007, 26, 2071-2082. [CrossRef]

47. Ito, Y.; Katsura, K.; Maruyama, K.; Taji, T.; Kobayashi, M.; Seki, M.; Shinozaki, K.; Yamaguchi-Shinozaki, K. Functional analysis of rice DREB1/CBF-type transcription factors involved in cold-responsive gene expression in transgenic rice. Plant Cell Physiol. 2006, 47, 141-153. [CrossRef]

48. Lin, R.-C.; Park, H.-J.; Wang, H.-Y. Role of Arabidopsis RAP2.4 in regulating light-and ethylene-mediated developmental processes and drought stress tolerance. Mol. Plant 2008, 1, 42-57. [CrossRef] 
49. Acosta-Motos, J.R.; Ortuño, M.F.; Bernal-Vicente, A.; Diaz-Vivancos, P.; Sanchez-Blanco, M.J.; Hernandez, J.A. Plant responses to salt stress: Adaptive mechanisms. Agronomy 2017, 7, 18. [CrossRef]

50. Umezawa, T.; Fujita, M.; Fujita, Y.; Yamaguchi-Shinozaki, K.; Shinozaki, K. Engineering drought tolerance in plants: Discovering and tailoring genes to unlock the future. Curr. Opin. Biotechnol. 2006, 17, 113-122. [CrossRef]

51. Nakashima, K.; Ito, Y.; Yamaguchi-Shinozaki, K. Transcriptional regulatory networks in response to abiotic stresses in Arabidopsis and grasses. Plant Physiol. 2009, 149, 88-95. [CrossRef] [PubMed]

52. Pardo, J.M. Biotechnology of water and salinity stress tolerance. Curr. Opin. Biotechnol. 2010, 21, 185-196. [CrossRef]

53. Yang, S.; Vanderbeld, B.; Wan, J.; Huang, Y. Narrowing down the targets: Towards successful genetic engineering of droughttolerant crops. Mol. Plant 2010, 3, 469-490. [CrossRef] [PubMed]

54. Islam, M.A.; Du, H.; Ning, J.; Ye, H.; Xiong, L. Characterization of Glossy1-homologous genes in rice involved in leaf wax accumulation and drought resistance. Plant Mol. Biol. 2009, 70, 443-456.

55. Oh, S.-J.; Kim, Y.S.; Kwon, C.-W.; Park, H.K.; Jeong, J.S.; Kim, J.-K. Overexpression of the transcription factor AP37 in rice improves grain yield under drought conditions. Plant Physiol. 2009, 150, 1368-1379. [CrossRef]

56. Xiao, B.-Z.; Chen, X.; Xiang, C.-B.; Tang, N.; Zhang, Q.-F.; Xiong, L.-Z. Evaluation of seven function-known candidate genes for their effects on improving drought resistance of transgenic rice under field conditions. Mol. Plant 2009, 2, 73-83. [CrossRef] [PubMed]

57. Du, H.; Wang, N.; Cui, F.; Li, X.; Xiao, J.; Xiong, L. Characterization of the $\beta$-carotene hydroxylase gene DSM2 conferring drought and oxidative stress resistance by increasing xanthophylls and abscisic acid synthesis in rice. Plant Physiol. 2010, 154, 1304-1318. [PubMed]

58. Jeong, J.S.; Kim, Y.S.; Baek, K.H.; Jung, H.; Ha, S.-H.; Do Choi, Y.; Kim, M.; Reuzeau, C.; Kim, J.-K. Root-specific expression of OsNAC10 improves drought tolerance and grain yield in rice under field drought conditions. Plant Physiol. 2010, 153, 185-197. [CrossRef]

59. Kumar, A.; Bernier, J.; Verulkar, S.; Lafitte, H.; Atlin, G. Breeding for drought tolerance: Direct selection for yield, response to selection and use of drought-tolerant donors in upland and lowland-adapted populations. Field Crops Res. 2008, 107, 221-231. [CrossRef]

60. Pellegrineschi, A.; Reynolds, M.; Pacheco, M.; Brito, R.M.; Almeraya, R.; Yamaguchi-Shinozaki, K.; Hoisington, D. Stress-induced expression in wheat of the Arabidopsis thaliana DREB1A gene delays water stress symptoms under greenhouse conditions. Genome 2004, 47, 493-500.

61. Hiei, Y.; Ohta, S.; Komari, T.; Kumashiro, T. Efficient transformation of rice (Oryza sativa L.) mediated by Agrobacterium and sequence analysis of the boundaries of the T-DNA. Plant J. 1994, 6, 271-282. [CrossRef] [PubMed]

62. Lin, Y.J.; Zhang, Q. Optimising the tissue culture conditions for high efficiency transformation of indica rice. Plant Cell Rep. 2005, 23, 540-547. [CrossRef] [PubMed]

63. Ausubel, F.; Brent, R.; Kingston, R.; Moore, D.; Seidman, J.; Smith, J.; Struhl, K. Current Protocols in Molecular Biology; John Wiley \& Sons Inc.: Hoboken, NJ, USA, 2003; Volume 1.

64. Ausubel, F.M.; Brent, R.; Kingston, R.E.; Moore, D.; Seidman, J.; Smith, J.T.; Struhl, K. Short Protocols in Molecular Biology; John Wiley and Sons: Hoboken, NJ, USA, 1992.

65. Sambrook, H. Molecular Cloning: A Laboratory Manual; Cold Spring Harbor Laboratory Press: Cold Spring Harbor, NY, USA, 1989.

66. Barrs, H.; Weatherley, P. A re-examination of the relative turgidity technique for estimating water deficits in leaves. Aust. J. Biol. Sci. 1962, 15, 413-428. [CrossRef]

67. Puértolas, J.; Larsen, E.K.; Davies, W.J.; Dodd, I.C. Applying 'drought'to potted plants by maintaining suboptimal soil moisture improves plant water relations. J. Exp. Bot. 2017, 68, 2413-2424. [CrossRef] [PubMed]

68. Livak, K.J.; Schmittgen, T.D. Analysis of relative gene expression data using real-time quantitative PCR and the $2^{-\Delta \Delta C T}$ method. Methods 2001, 25, 402-408. [CrossRef]

69. Bewley, J.D.; Black, M. Physiology and Biochemistry of Seeds in Relation to Germination. V. 2. Viability, Dormancy, and Environmental Control; Springer: Heidelberg, Germany, 1982. 